\section{Delta blues}

Living on the flood plain of three great rivers, the people of Bangladesh endure floods, drought, water-borne disease and much else besides. Can they entertain any hope of relief? Tom Clarke investigates.

f Bangladesh were to count her blessings, they would number three: the Brahmaputra, the Meghna and the mighty Ganges. These great rivers are practically Bangladesh's only natural resources. In a predominately rural country in which agriculture and freshwater fishing are the linchpins of the economy, the rivers are the people's lifeblood.

But these blessings, allied with the region's summer monsoon climate, are also a curse. Although almost two metres of rain fall on Bangladesh each year, more than two-thirds arrive in just four months. For much of the year, the vast delta formed by the three rivers is parched, but in many summers their banks burst, causing massive floods. Lacking proper sanitation and water-storage facilities, Bangladesh is also prone to epidemics of water-borne disease. "Even during floods, the major problem is the availability of safe water," says environmental scientist Atiq Rahman, executive director of the Bangladesh Centre for Advanced Studies in Dhaka.

Climate change will only make matters worse, with shifting patterns of rainfall and rising sea levels threatening to render large tracts of agricultural land useless. Add a cruel and recently discovered twist - the poisoning of many millions of people by well water contaminated with arsenic - and it's clear that Bangladesh represents a challenging case study for anyone who wants to solve the world's water woes.

"Nowhere is water more dominant in people's lives," says John Soussan, a geographer at a branch of the Stockholm Environmental Institute at the University of York, UK, who studies water issues in Bangladesh. And nowhere better illustrates the complexity of producing workable solutions to waterresource problems. The threats that face

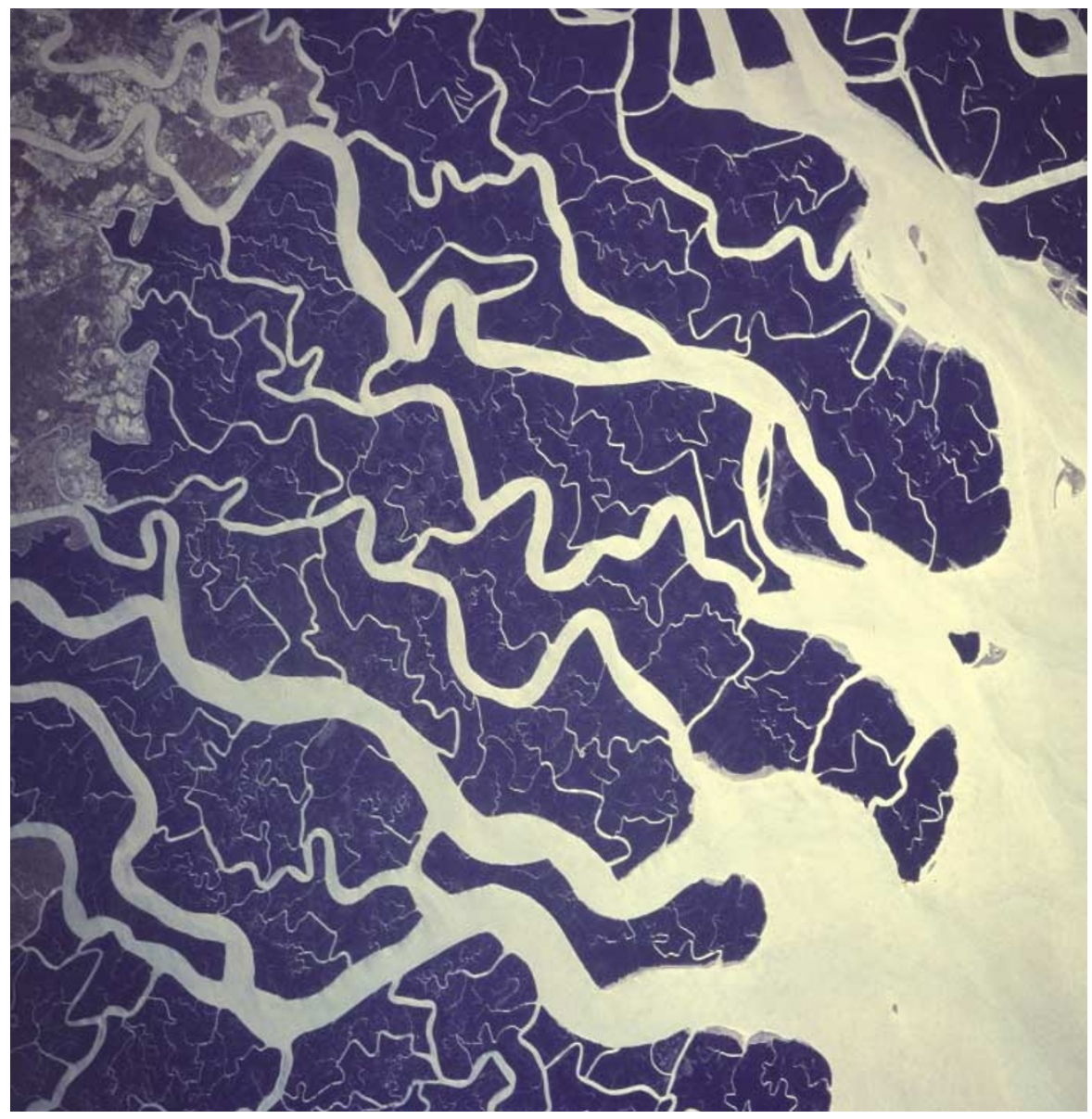

Water, water everywhere: but managing the Bengal Delta (pictured here from space) is far from simple.

Bangladesh's supplies are intimately interconnected: thwart one, and you can create problems downstream — sometimes literally.

\section{Political pressures}

Worse still, the issues are overlaid by fractious regional politics. For decades, Bangladesh has been in dispute with its neighbours - particularly India - over their management of the rivers that drain into Bangladeshi territory. For the country's politicians, water is the defining issue, and the Ganges - known in Bangladesh as the Padma - whose basin is home to some 400 million people, is a perennial bone of contention. Despite some progress in reaching agreement over the river's management, Bangladesh still blames India for holding back too much water in the dry season, and letting the floodgates open each time the monsoon threatens.

The picture looks bleak, but experts point out that Bangladesh is, in some ways, a victim of its own success. Given the hydrological hand they were dealt, the inhabitants of the Bengal Delta traditionally grew low-yielding but flood-tolerant rice, and fished wetlands and pools that were recharged by annual floods. This could support a modest population at subsistence levels, but no more. Since the late 1950s, however, aid-donor-backed irrigation schemes, later incorporating areas of fertile delta soil to the plough. Now almost all of the land in Bangladesh that is suitable for agriculture is used. High-yielding rice varieties have boosted productivity hugely, while the development of coastal areas for shrimp farming has also provided further food and revenue.

As a result, the population has quadrupled since 1950. Today, an average of 920 people crowd into each square kilometre of Bangladesh, making it one of the most densely populated countries in the world. Therein lies the problem: population pressure has helped to make droughts more severe and floods potentially more devastating. And with sanitation still inadequate, the rapid population growth of the past halfcentury has exacerbated problems with water-borne disease. Although the analogy won't endear him to many of his compatriots, Rahman likens Bangladesh to a giant toilet that is adequately flushed just once a year.

By the 1970s, it was clear that something World Bank and UNICEF — hit on the idea of sinking tube wells into the aquifers that lie beneath the delta's surface. Local people, fearful of this subterranean source, initially called it 'the Devil's water'. But when rates of diarrhoeal disease halved, the programme was deemed an unqualified success. By the groundwater pumping, have opened up vast had to be done, and aid agencies - led by the 
1990s, as many as 10 million wells had been sunk, many of them by local companies.

If only things were that simple: the tragedy that has subsequently unfolded reveals in stark terms how 'solutions' to water-resource problems can go spectacularly awry if our knowledge of a region's hydrology and geology is incomplete. It was Dipankar Chakraborti, an epidemiologist in the neighbouring Indian state of West Bengal, who first raised the alarm. In 1988, on a visit to his Bengali parents' rural village, Chakraborti noticed that many local people were suffering from skin lesions and cancers that seemed to be consistent with arsenic poisoning. When he tested samples of well water in his laboratory at Jadavpur Universityin Calcutta, it became clear why: the villagers' water supply was massively tainted with the metal.

\section{Drinking problem}

Over the ensuing five years, Chakraborti and his colleagues at Dhaka Community Hospital showed that the problem extends across large areas of the Bengal Delta on both sides of the India-Bangladesh border ${ }^{1}$. Some wells contain 400 times the World Health Organization (WHO) safe drinking-water standard for arsenic. Current estimates are that 80 million Bangladeshis are at risk, with 30 million drinking water containing five times the WHO arsenic limit. "The danger is very, very real," says Chakraborti.

The arsenic was washed from the sediments of the Himalayas, and is thought to have been accumulating in the silt beneath the Bengal Delta for at least 2 million years ${ }^{2}$. The puzzle is why it is now being drawn to the surface in some wells, but not in others. One leading theory is that the arsenic is released from the sediments into groundwater under oxygen-free, reducing conditions. And some researchers suspect that rotting vegetation in the uppermost 30 metres or so of sediment creates just such an environment. That would help to explain why the problem seems worse in shallower wells, and adds to hopes that it may be possible to identify and selectively shut down those that are hazardous.

But recent research from a team led by Shafiqul Islam, a Bangladeshi hydrologist now at the University of Cincinnati in Ohio, suggests that the pumping of groundwater for irrigation seems to be drawing arsenic into deeper wells ${ }^{3}$. The mechanism remains unclear, but Islam suspects that deep groundwater is being replaced by surface water that is rich in organic material, which then mobilizes previously insoluble arsenic. Chakraborti has also found that wells that his group tested and marked as safe had become dangerous when surveyed again a few years later.

What's more, drinking water may not be the only hazard: rice crops irrigated with arsenic-contaminated groundwater have now been shown to accumulate the toxic element ${ }^{4}$.

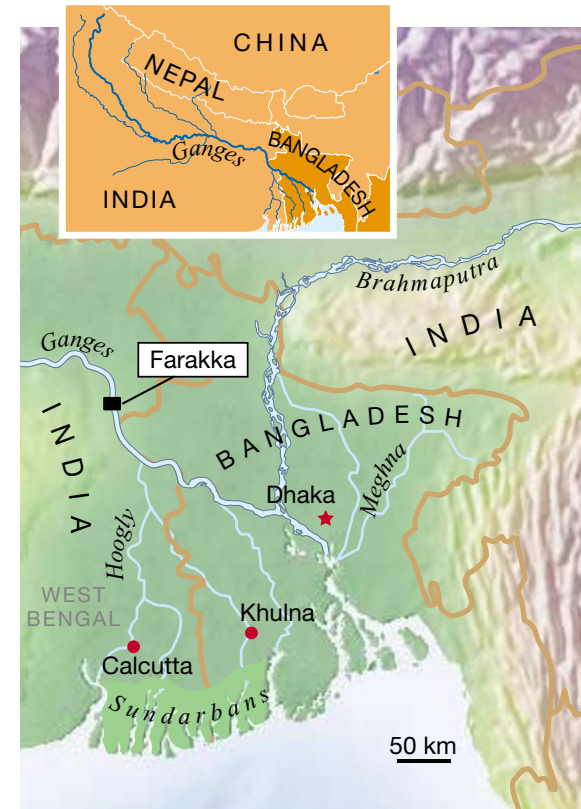

Although it's too early to tell whether this poses a serious threat, the finding has sown seeds of doubt about the use of aquifer water for irrigation, which is the mainstay of Bangladesh's agriculture.

Research and new technology will be central to tackling the arsenic problem. Surveying and screening wells is a top priority, yet arsenic-testing kits for use in the field are still unreliable ${ }^{5}$. More work is also needed to confirm the conditions under which arsenic is mobilized from the sediments, and at what depths this occurs.

Glut and dried: Bangladesh's monsoon climate has locked the country into a cycle of flooding (below) and drought (inset), which has been exacerbated by its own water-management efforts and those of its neighbour India.
Even if the arsenic issue can be resolved, that still leaves the difficulty of living with Bangladesh's annual cycle of flood and drought. The floods can be lethal on a massive scale: those of 1974, together with the famine and water-borne disease that followed, killed 30,000. Such tolls led to the construction of nearly 7,000 kilometres of embankments to contain the delta's rivers. But they couldn't prevent $55 \%$ of the country from being inundated in 1988, when 2,000 people died.

What has followed represents a small victory for science-based watershed management. Initially, the Bangladeshi government stuck to a plan that relied on further huge engineering projects. But by the late 1980s, academic scientists at the Bangladesh Centre for Advanced Studies and elsewhere were revealing the pitfalls of relying too heavily on engineering solutions. Although embankments may stop floods, they also prevent water from dissipating when they are breached, delaying recovery from floods and ruining harvests that might otherwise have survived temporary submersion. The embankments were also preventing waters laden with fish fry from replenishing the country's wetlands ${ }^{6}$. "In some cases the infrastructure caused more problems than it solved," says Matthew Chadwick, a colleague of Soussan at the University of York.

After "a hell of a lot of convincing", the government was persuaded to rethink its strategy, says Rahman. While still relying on

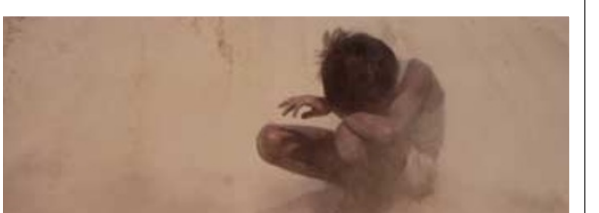


engineering solutions to protect major popto evacuating people from areas that were threatened with temporary inundation.

This revised approach seems to be working better. When the worst floods in Bangladesh's history struck in 1998, submerging two-thirds of the country, 22 million people were displaced, but just 700 lost their lives. "People are learning to live with floods," asserts Saleem Huq, formerly an adviser to the Bangladeshi government on the environment and now based in London at the International Institute for Environment and Development.

\section{Dam nation}

This may be so, but less progress has been made in tackling the other side of Bangladesh's cycle of hydrological poverty and excess. The flow of the country's rivers naturally declines during the height of the dry season, from March to May. But for the Ganges, the problem has been exacerbated by India's construction of the Farakka Barrage, 20 kilometres upstream of the Bangladeshi border. Completed in 1974, the dam diverts water from the Ganges into the Hoogly River, which feeds Calcutta. Following its construction, dry-season flows of the river through Bangladesh were drastically curtailed (see table, below).

The first trials of the barrage poisoned Indian-Bangladeshi relations. It took three years, and several appeals by Bangladesh to the United Nations, to negotiate a five-year water-sharing deal. Such temporary agreements persisted until 1988, when talks broke down amid renewed hostility. Hope was revived in 1996, when the two countries signed a 30-year Ganges Water Treaty, which requires both countries to monitor flows and negotiate shares in the river's water the during the dry season.

Yet despite the treaty, it is thought that less water flows through southwestern Bangladesh in the dry season now than it did in the 1970s. As a result, the Ganges dumps more of its silt in the channels of the delta, rather than in the Bay of Bengal. "It's like cholesterol getting into your arteries," observes Islam. This symptom has further reduced flow in some regions, creating a vicious cycle of hydrological deterioration.

The curtailed flow is also causing problems in Bangladesh's coastal zone, which forms a porous buffer between the Bay of Bengal and the fertile delta soils. As the flow of fresh water falters, salt water is advancing to replace it in the southwest corner of the country, downstream of the Farakka Barrage. In conservation terms, it couldn't ulation centres, the focus elswhere was shifted

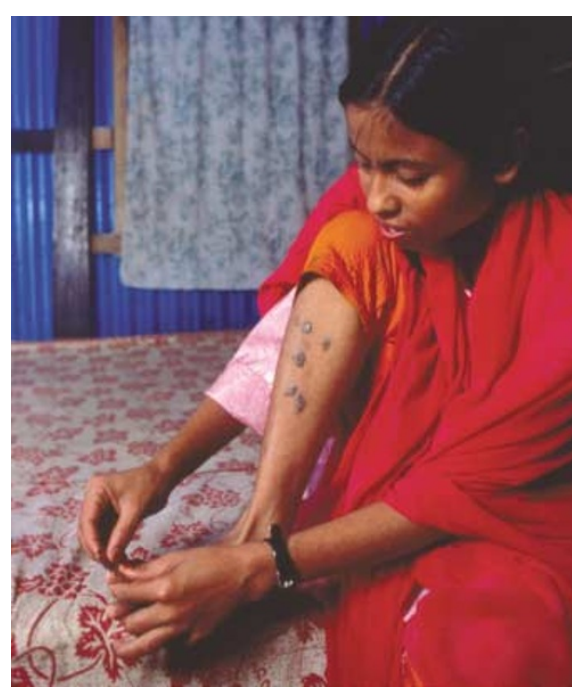

Water marks: skin lesions, a symptom of arsenic poisoning, are rife among the delta's inhabitants.

be happening in a worse place. That region hosts the Sunderbans - the largest expanse of mangrove forest in the world - which provide habitat for the endangered Bengal tiger (Panthera tigris tigris), estuarine crocodile (Crocodylus porosus) and Indian python (Python molurus molurus), as well as 260 species of birds. Already, the tops of the forest's eponymous Sundari trees (Heritiera fomes) are beginning to die back - a telltale sign of excess salinity.

Agriculture and drinking water are also threatened. Around the town of Khulna on the fringes of the Sunderbans, well water is now too salty during the dry season for irrigation and drinking. The advancing salt water brings with it marine plankton, including miniature crustaceans known as copepods. Although harmless in themselves, the copepods' body surfaces are the preferred home for Vibrio cholerae, the bacterium that causes cholera - and saltwater intrusion has already been linked to unusually severe outbreaks of the disease in Bangladesh ${ }^{7}$.

Climate change could make matters worse still. Recent research by climatologist Peter Webster at the Georgia Institute of Technology in Atlanta predicts that an El Niño-like phenomenon that causes fluctuations in sea level in the Bay of Bengal will intensify. This, coupled with even a slight rise in global sea level, could seriously accelerate saltwater intrusion. At the same time, the cyclones that batter the Bangladeshi coast may become more intense, as will the monsoon rains ${ }^{8}$ - leading most experts to suspect that Bangladesh's flood-drought dichotomy will become more pronounced.

Faced with its current difficulties and the prospect of worse to come, experts agree that

Mean monthly flows in the Ganges $\left(\mathrm{m}^{3}\right)$

\begin{tabular}{lllllllllllll} 
& Jan & Feb & Mar & Apr & May & Jun & Jul & Aug & Sept & Oct & Nov & Dec \\
\hline $\mathbf{1 9 3 4 - 7 4}$ & 3,090 & 2,668 & 2,287 & 2,031 & 2,176 & 4,489 & 17,290 & 38,348 & 36,063 & 17,870 & 7,091 & 4,180 \\
\hline $\mathbf{1 9 7 4 - 8 8}$ & 1,932 & 1,482 & 1,155 & 1,063 & 1,450 & 3,569 & 20,111 & 40,183 & 39,233 & 16,685 & 5,730 & 2,493
\end{tabular}

the solution lies in integrated waterresource management' - a comprehensive plan that takes account of all of Bangladesh's interconnected water problems. "There needs to be clarity of concept, not just a bunch of random projects," argues Rahman.

Emerging scientific tools should help. Last month, for instance, at the annual meeting of the American Association for the Advancement of Science in Denver, Colorado, Webster unveiled a monsoon model that provided accurate 25-day forecasts of rainfall over the entire Ganges basin in 2002. This model should provide more time for emergency planners to house displaced people during the most severe floods. "Farmers can make informed decisions, too, either harvesting early or planting late," says Webster.

There is even a draft National Water Management Plan on the table. Commissioned by the Bangladeshi government from the infrastructure consultancy firm Halcrow and completed in 2001, the plan calls for an integrated approach to water management. It also recommends greater decentralization to hand more decisions on resource allocation over to local governments who are within earshot of the needs of water users. It's a radical plan, and not without its critics, but many experts agree that it would be a significant step in the right direction.

The stumbling block, as is so often the case, may be at the political level. For a start, the plan was commissioned by a previous administration, and the new government has yet to embrace it. More fundamentally, the goal of decentralization may not yet be practical. "There are huge gaps in the system of local government," says Soussan. In short, Bangladesh needs help in training a generation of technocrats to take ownership of its water-resource problems.

For experts who have devoted their professional energies to studying Bangladesh's water problems, it would be an unforgivable tragedy if these obstacles proved to be insurmountable. "There's enough knowledge out there to address the problems," concludes Chadwick. "Now we really need to start putting some of these ideas into practice." Tom Clarke works in Nature's news syndication team.

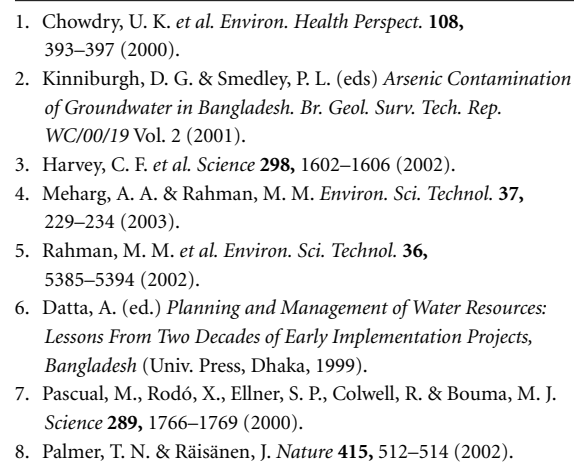

6. Datta, A. (ed.) Planning and Management of Water Resources: Lessons From Two Decades of Early Implementation Projects, Bangladesh (Univ. Press, Dhaka, 1999).

7. Pascual, M., Rodó, X., Ellner, S. P., Colwell, R. \& Bouma, M. J. Science 289, 1766-1769 (2000).

8. Palmer, T. N. \& Räisänen, J. Nature 415, 512-514 (2002). 